\title{
KAJIAN EFIKASI HERBISIDA AMETRIN DAN KOMBINASI AMETRIN + (2,4-D ATAU METIL METSULFURON) TERHADAP PERTUMBUHAN GULMA PADA BUDIDAYA TANAMAN TEBU LAHAN KERING
}

\author{
Study of Eficacy Ametrine Herbicide, and Ametrine + (2,4-D or Metsulfuron) Combination \\ on Weeds Growth in Dry Land Plant Cane Cultivation \\ Herry Susanto $^{1) *}$, Rusdi Evizal ${ }^{1)}$, dan Sugiatno ${ }^{1)}$ \\ 1) Jurusan Agroteknologi, Fakultas Pertanian, Universitas Lampung \\ Jalan Sumantri Brojonegoro No. 1 Bandar Lampung, 35145 \\ *E-mail: herrysusanto63al@gmail.com
}

\begin{abstract}
ABSTRAK
Salah satu kendala dalam produksi gula adalah pertumbuhan gulma terutama selama periode kritis yaitu sampai 12 minggu setelah penanaman. Pengendalian gulma dalam budidaya tebu lahan kering biasanya dilakukan secara kimiawi dengan aplikasi herbisida pratumbuh saat penanaman hingga 1 minggu dan pasca-tumbuh selama sekitar 2,5 bulan. Herbisida pratumbuh biasanya digunakan untuk mengendalikan gulma umur 0-2 bulan dan 2,5 bulan herbisida pascatumbuh untuk mempersiapkan pemupukan kedua. Perlakuan peneliitian terdiri dari: herbisida ametrine $80 \%$ dengan dosis 0,$8 ; 1,2 ; 1,6,2,0 ;$ dan $2,4 \mathrm{~kg} /$ ha, ametrine 1,6 kg / ha +2,4-D 865g l/ ha, ametrine 1,6 kg / ha + metil metsulfuron $8 \mathrm{~g} / \mathrm{ha}, 2 \mathrm{kali}$ perawatan penyiangan manual, dan kontrol. Rancangan yang digunakan adalah rancangan acak kelompok dengan 4 ulangan. Hasil penelitian menunjukkan bahwa herbisida ametrin dan ametrin $+2,4-$ $\mathrm{D}$ atau metsulfuron metil mampu menekan pertumbuhan gulma total dalam budidaya tebu lahan kering. Ametrin dan ametrin + 2,4-D atau metsulfuron metil semua dosis mampu menekan gulma Borreria alata, Rhicardia brasiliensis, dan Digitaria longifolia; kecuali pada dosis ametrine 0,8 dan $1,2 \mathrm{~kg} / \mathrm{ha}$ terhadap Borreria alata pada 8 dan 12 minggu setelah aplikasi. Sedangkan gulma yang tidak terkendali dengan semua perlakuan, yaitu Brachiaria sp., Cyperus rotundus, dan Cleome rutidosperma. Pertumbuhan tanaman tebu tidak ditekan oleh Penyemprotan herbisida ametrin dan ametrin $+2,4-\mathrm{D}$ atau metsulfuron metil dan juga penyiangan secara manual. Penyemprotan herbisida ametrine dan ametrine + 2,4-D atau metsulfuron metil tidak meracuni tanaman tebu.
\end{abstract}

Kata kunci: Ametrin, herbisida, tebu

\section{ABSTRACT}

Weed control in dry land cane cultivation is usually done chemically with the pre-emergence herbicides spraying since planting until to one week and post-emergence for about 2.5 months. Pre-emergence herbicides are usually used to control weeds when planting until to 2 month periode and 2.5 months post-emergence herbicides to prepare a second fertilization so that sugar cane growth is not disturbed by weeds. The treatment consisted of: ametrine $80 \%$ herbicide at doses of $0.8,1.2,1.6,2.0$; and $2.4 \mathrm{~kg}$ / ha, ametrine $1.6 \mathrm{~kg} / \mathrm{ha}+2,4-\mathrm{D} 865 \mathrm{~g} \mathrm{l} / \mathrm{ha}$, ametrine $1.6 \mathrm{~kg} / \mathrm{ha}+$ metil metsulfuron $8 \mathrm{~g} / \mathrm{ha}$, 2 times manual weeding treatment, and control. The experimental design used was randomized block design with 4 replications. The results showed that the herbicides ametrine and ametrine $+2,4-D$ or metsulfuron methyl were able to suppress the total weeds growth in the cultivation of dry land sugarcane. Ametrine and ametrine + 2,4-D or metsulfuron methyl all doses are able to suppress weeds Borreria alata, Rhicardia brasiliensis, and Digitaria longifolia; except at doses of ametrine 0.8 and $1.2 \mathrm{~kg} / \mathrm{ha}$ against Borreria alata at 8 and 12 weeks after application. Whereas weeds that are not controlled with all treatments, namely Brachiaria sp., Cyperus rotundus, and Cleome rutidosperma. The growth of plant cane is not suppressed by the treatment of herbicide ametrine and ametrine $+2,4-D$ or metsulfuron methyl and as well as manual weeding. The treatment of herbicide ametrine and ametrine $+2,4-D$ or metsulfuron methyl does not cause toxic in plant cane cultivation.

Keywords: Ametrine, 2,4-D, metsulfuron methy, plant cane, weeds. 


\section{PENDAHULUAN}

Tebu merupakan komoditas utama penghasil gula sebagai bahan pokok yang sangat diperlukan masyarakat saat ini masih tidak mencukupi kebutuhan konsumsi dibandingkan produksi yang didapatkan. Hal tersebut terjadi dikarenakan produktivitas tebu sebagai penghasil gula kurang optimum dan masih jauh dari kebutuhan yang selalu meningkat terus. Salah satu hal yang menjadi penyebab kurang produktifnya tanaman ini dikarenakan adanya gulma. Keberadaan gulma di areal pertanaman tebu menjadi masalah penting sejak penyiapan lahan, pembibitan, tanaman muda hingga tanaman siap panen; tetapi hal yang paling utama dalam menurunkan produktivitas adalah saat periode kritis tanaman sekitar 3 bulan pertama dari saat tanam tebu yaitu pada fase perkecambahan dan pertumbuhan anakan tebu (Evizal, 2018). Kehadiran gulma dapat menjadi kompetitor terhadap tanaman dalam mendapatkan unsur hara, air, $\mathrm{CO}_{2}$, cahaya matahari dan ruang tempat tumbuh, serta ada kemungkinan gulma menjadi inang hama dan penyakit tanaman (Sembodo, 2010 dan Pujisiswanto, 2012).

Pengendalian gulma di pertanaman tebu lahan kering yang arealnya sangat luas umumnya dilakukan secara kimiawi menggunakan herbisida pratumbuh maupun pascatumbuh. Menurut Monaco et al. (2002) dan Baron et al. (2008) herbisida ametrin bersifat selektif untuk mengendalikan gulma rumput dan daun lebar, sedangkan herbisida 2,4-D maupun metil metsulfuron bersifat selektif untuk gulma daun lebar dan teki (Adnyana, 2017) apabila dikombinasi dengan ametrin diharapkan dapat meningkatkan efikasinya.

\section{METODE PENELITIAN}

\section{Alat dan Bahan}

Alat aplikasi herbisida dengan menggunakan sprayer punggung merek
Matabi bernosel merah (dengan lebar bidang semprot $2 \mathrm{~m}$ ) serta kelengkapan sebelum dan saat penyemprotan yang diperlukan seperti timbangan, ember, dan gelas ukur. Untuk keperluan analisis vegetasi digunakan kuadran berukuran $0,5 \mathrm{~m} \times 0,5 \mathrm{~m}$, cutter, oven, dan timbangan. Bahan yang digunakan herbisida ametrin $80 \%$, 2,4-D, metil metsulfuron $20 \%$, dan bibit tebu varietas GM 23.

\section{Rancangan Percobaan}

Penelitian menggunakan metode Rancangan Acak Kelompok (RAK) dengan 4 ulangan. Perlakuan terdiri dari : herbisida berbahan aktif ametrin $80 \%$ dengan dosis 0,$8 ; 1,2 ; 1,6 ; 2,0 ; 2,4 \mathrm{~kg} / \mathrm{ha}$, ametrin 1,6 $\mathrm{kg} / \mathrm{ha}+2,4-\mathrm{D} 865 \mathrm{~g} / \mathrm{ha}$ ametrin $1,6 \mathrm{~kg} / \mathrm{ha}+$ metil metsulfuron $8 \mathrm{~g} / \mathrm{ha}$ perlakuan penyiangan manual $2 \mathrm{kali}$, dan kontrol.

\section{Tahapan Penelitian}

Satu satuan dalam percobaan ini adalah petakan yang terdiri dari 5 juring tanaman tebu dengan panjang juring $10 \mathrm{~m}$ dan jarak antarjuring $1,5 \mathrm{~m}$ serta antar ulangan $2 \mathrm{~m}$. Jumlah bibit yang digunakan setek terdiri mata tunas 10 per meter. Pengaturan letak percobaan dan kelompok diusahakan sedemikian rupa sehingga lokasi percobaan dengan kondisi gulma sasaran yang merata.

Aplikasi herbisida secara merata dilakukan sekali secara pratumbuh saat tiga hari setelah tanam dengan volume semprot 480 1/ha..

Pengamatan gulma dilakukan pada petak contoh berukuran $0,5 \mathrm{~m} \times 0,5 \mathrm{~m}$. Jumlah petak contoh yang diambil dua untuk setiap satuan petak percobaan pada setiap pengambilan sampel gulma. Letak petak contoh ditentukan secara sistematis.

Pengambilan gulma contoh dilakukan dengan cara memotong gulma tepat pada permukaan tanah. Gulma yang telah diambil dipilah-pilah menurut spesiesnya dan dikeringkan dengan menggunakan oven pada suhu $80^{\circ} \mathrm{C}$ selama 48 jam atau sampai 
mencapai bobot konstan. pengamatan gulma dilakukan pada 4, 8, dan 12 minggu setelah aplikasi herbisida (MSA).

Pengamatan fitotoksisitas herbisida terhadap tanaman tebu pada 2, 4, 6 dan 8 MSA secara skoring visual berikut:

$0=$ tidak ada keracunan, $0-5 \%$ bentuk dan atau warna daun muda tidak normal.

$1=$ keracunan ringan, $>5-20 \%$ bentuk dan atau warna daun muda tidak normal.

$2=$ keracunan sedang, $>20-50 \%$ bentuk dan atau warna daun muda tidak normal.

$3=$ keracunan berat. $>50-75 \%$ bentuk dan atau warna daun muda tidak normal.

$4=$ keracunan sangat berat, $>75 \%$ bentuk dan atau warna daun muda tidak normal hingga mengering dan tanaman mati. (Kementrian Pertanian, 2012).

Pengamatan fitotoksisitas herbisida terhadap tanaman dilakukan pada semua tanaman dengan cara membandingkan dengan perlakuan herbisida dan penyiangan manual.

Semua data yang diperoleh diolah dengan menggunakan analisis ragam dan untuk membedakan nilai tengah perlakuan digunakan uji Beda Nyata Terkecil tingkat perbedaan nilai tengah pada taraf $5 \%$.
Efikasi herbisida yang diuji disimpulkan dengan analisis data bobot kering spesies gulma sasaran. Herbisida yang diuji dinyatakan efektif apabila biomassa gulma pada perlakuan herbisida relatif sama atau lebih baik dibanding dengan perlakuan penyiangan manual dan nyata lebih ringan dibanding dengan kontrol, dapat mengendalikan gulma sampai 12 minggu setelah aplikasi, serta keracunan yang ditolerir adalah keracunan ringan.

\section{HASIL DAN PEMBAHASAN}

\section{Pertumbuhan Gulma}

Kondisi gulma setelah aplikasi herbisida ametrin dan kombinasi ametrin dan 2,4-D atau metil metsulfuron terdapat 6 jenis gulma utama yaitu Borreria alata, Cleome rutidosperma, Rhicardia brasiliensis, Brachiaria sp, Digitaria longifolia, dan Cyperus rotundus. Dari Tabel 1 semua dosis perlakuan herbisida maupun penyiangan manual mampu menekan bobot kering gulma total dari 4 hingga 12 MSA, kecuali penyiangan manual 4 MSA.

Tabel 1. Bobot kering gulma total akibat perlakuan herbisida ametrin dan kombinasinya

\begin{tabular}{|c|c|c|c|}
\hline \multirow[b]{2}{*}{ Perlakuan } & 4 MSA & $8 \mathrm{MSA}$ & $12 \mathrm{MSA}$ \\
\hline & \multicolumn{3}{|c|}{$\mathrm{g} / 0.5 \mathrm{~m}^{2}$} \\
\hline Ametrin $0,8 \mathrm{~kg} / \mathrm{ha}$ & $2,41 \mathrm{bc}$ & $35,99 \mathrm{~b}$ & $93,33 \mathrm{~b}$ \\
\hline Ametrin $1,2 \mathrm{~kg} / \mathrm{ha}$ & $1,60 \mathrm{bc}$ & $22,42 \mathrm{~b}$ & $110,43 \mathrm{~b}$ \\
\hline Ametrin $1,6 \mathrm{~kg} / \mathrm{ha}$ & $0,63 \mathrm{c}$ & $23,72 \mathrm{~b}$ & $78,43 \mathrm{~b}$ \\
\hline Ametrin $2,0 \mathrm{~kg} / \mathrm{ha}$ & $2,13 \mathrm{bc}$ & $4,19 \mathrm{~b}$ & $72,20 \mathrm{~b}$ \\
\hline Ametrin $2,4 \mathrm{~kg} / \mathrm{ha}$ & $1,95 \mathrm{bc}$ & $31,70 \mathrm{~b}$ & $91,13 \mathrm{~b}$ \\
\hline Ametrin 1,6 kg/ha+2,4-D 865g l/ha & $1,99 \mathrm{bc}$ & $12,82 \mathrm{~b}$ & $72,15 b$ \\
\hline Ametrin $1,6 \mathrm{~kg} / \mathrm{ha}+$ metil metsulfuron $8 \mathrm{~g} / \mathrm{ha}$ & $3,57 \mathrm{bc}$ & $5,42 \mathrm{~b}$ & $75,40 \mathrm{~b}$ \\
\hline Penyiangan manual & $4,49 \mathrm{ab}$ & $6,03 \mathrm{~b}$ & $63,65 \mathrm{~b}$ \\
\hline Kontrol & $6,03 \mathrm{a}$ & $129,32 \mathrm{a}$ & $178,82 \mathrm{a}$ \\
\hline BNT 0,05 & 3,17 & 48,44 & 47,71 \\
\hline
\end{tabular}

Keterangan: Nilai selajur yang diikuti huruf sama tidak berbeda menurut uji BNT 0,05 MSA $=$ Minggu setalah aplikasi

\section{Bobot Kering Gulma Dominan}

Penentuan jenis gulma dominan dilakukan berdasarkan perhitungan nibah dominan rasio gulma yang tumbuh di areal percobaab (Tjitrosoedirdjo, et al. 1984).
Bobot kering gulma dominan yang terkendali dengan perlakuan herbisida ametrin dan kombinasi ametrin $+2,4-\mathrm{D}$ atau metil metsulfuron pada Tabel 2 - 4 semua dosis dari 4 hingga 12 MSA adalah 
Richardia brasiliensis dan Digitaria longifolia, ketiga jenis ini termasuk golongan rumput dan daun yang dapat dikendalikan ametrin (Monaco et al. 2008). Gulma Borreria alata terkendali pada semua dosis perlakuan herbisida ametrin saat 4 MSA, sedangkan pada $8-12$ MSA hanya dosis $1,6-2,4 \mathrm{~kg} / \mathrm{ha}$ yang masih mampu menekan pertumbuhan gulma ini (Tabel 3). Perlakuan herbisida ametrin dalam menekan pertumbuhan gulma Richardia brasiliensis, Digitaria longifolia, dan Borreria alata sama atau lebih baik dari penyiangan manual dua kali serta lebih baik dibandingkan kontrol; sehingga dapat diambil kesimpulan bahwa ketiga gulma tersebut dapat terkendali dengan herbisida ametrin juga ametrin dan kombinasinya. Brachiaria sp., Cyperus rotundus dan Cleome rutidosperma adalah tiga dari enam jenis gulma dominan yang tidak terkendali dengan perlakuan herbisida ametrin dan kombinasinya maupun penyiangan manual dua kali, sehingga ketiga jenis gulma ini tidak ditampilkan.

Tabel 2. Bobot Digitaria longifolia akibat perlakuan herbisida ametrin dan kombinasinya

\begin{tabular}{|c|c|c|c|}
\hline \multirow[t]{2}{*}{ Perlakuan } & $4 \mathrm{MSA}$ & $8 \mathrm{MSA}$ & $12 \mathrm{MSA}$ \\
\hline & \multicolumn{3}{|c|}{$\mathrm{g} / 0.5 \mathrm{~m}^{2}$} \\
\hline Ametrin $0,8 \mathrm{~kg} / \mathrm{ha}$ & $0,26 \mathrm{~b}$ & $0,00 \mathrm{~b}$ & $1,43 \mathrm{~b}$ \\
\hline Ametrin $1,2 \mathrm{~kg} / \mathrm{ha}$ & $0,25 \mathrm{~b}$ & $0,00 \mathrm{~b}$ & $0,80 \mathrm{~b}$ \\
\hline Ametrin $1,6 \mathrm{~kg} / \mathrm{ha}$ & $0,13 \mathrm{~b}$ & $0,00 \mathrm{~b}$ & $0,60 \mathrm{~b}$ \\
\hline Ametrin $2,0 \mathrm{~kg} / \mathrm{ha}$ & $0,00 \mathrm{~b}$ & $0,00 \mathrm{~b}$ & $0,58 \mathrm{~b}$ \\
\hline Ametrin $2,4 \mathrm{~kg} / \mathrm{ha}$ & $0,00 \mathrm{~b}$ & $0,00 \mathrm{~b}$ & $0,45 \mathrm{~b}$ \\
\hline Ametrin $1,6 \mathrm{~kg} / \mathrm{ha}+2,4-\mathrm{D} 865 \mathrm{~g} l / \mathrm{ha}$ & $0,03 \mathrm{~b}$ & $0,03 \mathrm{~b}$ & $0,01 \mathrm{~b}$ \\
\hline Ametrin $1,6 \mathrm{~kg} / \mathrm{ha}+$ metil metsulfuron $8 \mathrm{~g} / \mathrm{ha}$ & $0,25 \mathrm{~b}$ & $0,01 \mathrm{~b}$ & $0,02 \mathrm{~b}$ \\
\hline Penyiangan manual & $1,83 \mathrm{a}$ & $4,23 \mathrm{~b}$ & $1,60 \mathrm{~b}$ \\
\hline Kontrol & $2,35 \mathrm{a}$ & 50,08 a & $20,28 \mathrm{a}$ \\
\hline BNT 0,05 & 1,44 & 22,27 & 2,71 \\
\hline
\end{tabular}

Keterangan: Nilai selajur yang diikuti huruf sama tidak berbeda menurut uji BNT 0,05

MSA = Minggu setalah aplikasi

Tabel 3. Bobot kering Borreria alata akibat perlakuan herbisida ametrin dan kombinasinya

\begin{tabular}{|c|c|c|c|}
\hline \multirow[b]{2}{*}{ Perlakuan } & $4 \mathrm{MSA}$ & $8 \mathrm{MSA}$ & $12 \mathrm{MSA}$ \\
\hline & \multicolumn{3}{|c|}{$\mathrm{g} / 0.5 \mathrm{~m}^{2}$} \\
\hline Ametrin $0,8 \mathrm{~kg} / \mathrm{ha}$ & $0,27 \mathrm{~b}$ & $9,26 \mathrm{ab}$ & $50,23 \mathrm{ab}$ \\
\hline Ametrin $1,2 \mathrm{~kg} / \mathrm{ha}$ & $0,22 \mathrm{~b}$ & $7,81 \mathrm{~b}$ & $25,55 \mathrm{~b}$ \\
\hline Ametrin $1,6 \mathrm{~kg} / \mathrm{ha}$ & $0,13 \mathrm{~b}$ & $0,00 \mathrm{~b}$ & $20,85 \mathrm{~b}$ \\
\hline Ametrin $2,0 \mathrm{~kg} / \mathrm{ha}$ & $0,04 \mathrm{~b}$ & $0,00 \mathrm{~b}$ & $21,55 \mathrm{~b}$ \\
\hline Ametrin $2,4 \mathrm{~kg} / \mathrm{ha}$ & $0,14 \mathrm{~b}$ & $2,34 \mathrm{~b}$ & $21,95 \mathrm{~b}$ \\
\hline Ametrin 1,6 kg/ha+2,4-D 865g l/ha & $0,26 \mathrm{~b}$ & $2,15 \mathrm{~b}$ & $8,31 \mathrm{~b}$ \\
\hline Ametrin $1,6 \mathrm{~kg} / \mathrm{ha}+$ metil metsulfuron $8 \mathrm{~g} / \mathrm{ha}$ & $0,01 \mathrm{~b}$ & $6,51 \mathrm{~b}$ & $18,79 \mathrm{~b}$ \\
\hline Penyiangan manual & $1,68 \mathrm{a}$ & $1,29 \mathrm{~b}$ & $41,00 a b$ \\
\hline Kontrol & $1,87 \mathrm{a}$ & 25,89 a & 85,28 a \\
\hline BNT 0,05 & 0,87 & 17,64 & 50,47 \\
\hline
\end{tabular}

Keterangan: Nilai selajur yang diikuti huruf sama tidak berbeda menurut uji BNT 0,05

MSA = Minggu setalah aplikasi 
Tabel 4. Bobot Richardia brasiliensis akibat perlakuan herbisida ametrin dan kombinasinya

\begin{tabular}{|c|c|c|c|}
\hline \multirow[b]{2}{*}{ Perlakuan } & $4 \mathrm{MSA}$ & $8 \mathrm{MSA}$ & $12 \mathrm{MSA}$ \\
\hline & \multicolumn{3}{|c|}{$\mathrm{g} / 0.5 \mathrm{~m}^{2}$} \\
\hline Ametrin $0,8 \mathrm{~kg} / \mathrm{ha}$ & $0,00 \mathrm{~b}$ & $1,80 \mathrm{~b}$ & $1,15 \mathrm{~b}$ \\
\hline Ametrin $1,2 \mathrm{~kg} / \mathrm{ha}$ & $0,00 \mathrm{~b}$ & $0,00 \mathrm{~b}$ & $1,28 \mathrm{~b}$ \\
\hline Ametrin $1,6 \mathrm{~kg} / \mathrm{ha}$ & $0,00 \mathrm{~b}$ & $0,00 \mathrm{~b}$ & $1,58 \mathrm{~b}$ \\
\hline Ametrin $2,0 \mathrm{~kg} / \mathrm{ha}$ & $0,00 \mathrm{~b}$ & $0,73 \mathrm{~b}$ & $1,18 \mathrm{~b}$ \\
\hline Ametrin $2,4 \mathrm{~kg} / \mathrm{ha}$ & $0,02 \mathrm{~b}$ & $0,09 \mathrm{~b}$ & $0,00 \mathrm{~b}$ \\
\hline Ametrin 1,6 kg/ha+2,4-D 865g l/ha & $0,00 \mathrm{~b}$ & $0,00 \mathrm{~b}$ & $0,00 \mathrm{~b}$ \\
\hline Ametrin $1,6 \mathrm{~kg} / \mathrm{ha}+$ metil metsulfuron $8 \mathrm{~g} / \mathrm{ha}$ & $0,00 \mathrm{~b}$ & $0,00 \mathrm{~b}$ & $0,00 \mathrm{~b}$ \\
\hline Penyiangan manual & $0,07 \mathrm{~b}$ & $0,00 \mathrm{~b}$ & $0,00 \mathrm{~b}$ \\
\hline Kontrol & $1,06 \mathrm{a}$ & $11,01 \mathrm{a}$ & $28,53 \mathrm{a}$ \\
\hline BNT 0,05 & 0,52 & 4,63 & 20,97 \\
\hline
\end{tabular}

Keterangan: Nilai selajur yang diikuti huruf sama tidak berbeda menurut uji BNT 0,05 MSA = Minggu setalah aplikasi

\section{Pertumbuhan Tebu}

Pertumbuhan tanaman tebu dengan mengamati pertumbuhan populasi tanaman pada tiga baris/juring tanaman bagian tengah ditampilkan pada Tabel 5. Populasi tanaman tebu 4 hingga 8 MSA semua perlakuan masih tidak berbeda dengan kontrol maupun penyiangan manual. Hal tersebut dikarenakan antara kontrol maupun penyiangan manual kondisi pertumbuhan gulma masih sama. Pada 12 MSA menunjukkan bahwa perlakuan herbisida sama baiknya dengan penyiangan manual dan lebih baik dibandingkan dengan kontrol.

Dari hasil pengamatan pertumbuhan tebu tersebut perlakuan herbisida tidak menekan tanaman dan sama baiknya dibanding penyiangan manual sehingga herbisida ametrin 80 WP maupun ametrin dan kombinasinya dapat digunakan untuk pengendalian gulma pada budidaya tanaman tebu.

\section{Fitotoksisitas}

Pengamatan fitotoksisitas herbisida yang dilakukan pada 2, 4, dan 6 MSA terhadap tanaman tebu, perlakuan herbisida amatrin dan kombinasinya pada semua dosis yang diuji tidak menimbulkan keracunan pada tanaman tebu. Ametrin merupakan herbisida yang bersifat selektif terhadap tanaman tebu sehingga tidak menimbulkan keracunan pada tanaman (Baron et al., 2008).

Tabel 5. Populasi tebu pada 3 juring akibat perlakuan herbisida ametrin dan kombinasinya

\begin{tabular}{lccc}
\hline Perlakuan & \multicolumn{1}{c}{$4 \mathrm{MSA}$} & $8 \mathrm{MSA}$ & $12 \mathrm{MSA}$ \\
\hline Ametrin $0,8 \mathrm{~kg} / \mathrm{ha}$ & $171,0 \mathrm{a}$ & $263,3 \mathrm{a}$ & $311,8 \mathrm{~b}$ \\
Ametrin $1,2 \mathrm{~kg} / \mathrm{ha}$ & $176,8 \mathrm{a}$ & $271,0 \mathrm{a}$ & $310,3 \mathrm{~b}$ \\
Ametrin $1,6 \mathrm{~kg} / \mathrm{ha}$ & $171,8 \mathrm{a}$ & $274,8 \mathrm{a}$ & $317,0 \mathrm{ab}$ \\
Ametrin $2,0 \mathrm{~kg} / \mathrm{ha}$ & $173,0 \mathrm{a}$ & $262,3 \mathrm{a}$ & $318,0 \mathrm{ab}$ \\
Ametrin $2,4 \mathrm{~kg} / \mathrm{ha}$ & $180,0 \mathrm{a}$ & $273,0 \mathrm{a}$ & $326,0 \mathrm{a}$ \\
Ametrin $1,6 \mathrm{~kg} / \mathrm{ha}+2,4-D$ 865g $/ / \mathrm{ha}$ & $178,9 \mathrm{a}$ & $245,6 \mathrm{a}$ & $326,7 \mathrm{a}$ \\
Ametrin $1,6 \mathrm{~kg} / \mathrm{ha}+$ metil metsulfuron $8 \mathrm{~g} / \mathrm{ha}$ & $179,6 \mathrm{a}$ & $234,4 \mathrm{a}$ & $314,8 \mathrm{ab}$ \\
Penyiangan manual & $165,5 \mathrm{a}$ & $281,8 \mathrm{a}$ & $329,8 \mathrm{a}$ \\
Kontrol & $202,5 \mathrm{a}$ & $271,0 \mathrm{a}$ & $296,8 \mathrm{c}$ \\
BNT 0,05 & 39,6 & 67,2 & 14,1 \\
\hline
\end{tabular}

Keterangan: Nilai selajur yang diikuti huruf sama tidak berbeda menurut uji BNT 0,05 MSA = Minggu setalah aplikasi 


\section{KESIMPULAN}

Dari percobaan ini dapat diambil simpulan bahwa: herbisida ametrin $80 \%$ dan kombinasi ametrin $+2,4-\mathrm{D}$ atau metil metsulfuron mampu mengendalikan pertumbuhan gulma total pada budidaya tanaman tebu lahan kering. Herbisida ametrin dan kombinasi ametrin + 2,4-D atau metil metsulfuron pada semua dosis yang diuji mampu menekan gulma Rhicardia brasiliensis dan Digitaria longifolia; kecuali pada dosis ametrin 0,8 dan $1,2 \mathrm{~kg} / \mathrm{ha}$ terhadap Borreria alata pada 8 dan 12MSA. Sedangkan gulma yang tidak terkendali dengan semua perlakuan yaitu Brachiaria sp., Cyperus rotundus dan Cleome rutidosperma.

Pertumbuhan tanaman tebu tidak tertekan dengan perlakuan herbisida ametrin $80 \%$ dan ametrin + 2,4-D atau metil metsulfuron dan sama baiknya dengan penyiangan manual, meskipun tidak untuk dosis ametrin 0,8 dan $1,2 \mathrm{~kg} / \mathrm{ha}$ tidak walaupun masih lebih baik dibandingkan kontrol. Perlakuan herbisida ametrin dan ametrin + 2,4-D atau metil metsulfuron tidak mengakibatkan keracunan pada tanaman tebu.

\section{DAFTAR PUSTAKA}

Adnyana, I. M. M. 2017. Klasifikasi Respon Morfologi dan Respon Biokimia terhadap Herbisida. AGT Udayana. 49 p.

Baron, H. L., J. McFarland, dan O. Burnside. 2008. The Triazine Herbicide. Elsevier BV. San Diego.

Evizal, R. 2018. Pengelolaan Perkebunan Tebu. Graha Ilmu. Yogyakarta. 244 p.

Kementrian pertanian. 2012. Metode Atandar Pengujian Efikasi Herbisida Tahun 2012. Departemen Pertanian. Jakarta. 257 p.

Monaco, T. J., S. M. Weller, dan F. M. Ashton. 2002. Weed Science Principles and Practice $4^{\text {th }} e d$. Jhon Wiley \& son. New York. Pp 685

Pujisiswanto, H. 2012. Kajian Daya Racun Cuka (Asam Asetat) terhadap pertumbuhan gulma pada persiapan lahan. Agrin. 16 (1): 40-48.

Sembodo, D. R. J. 2010. Gulma dan Pengelolaannya. Graha Ilmu. Yogyakarta. $168 \mathrm{p}$.

Tjitrosoedirdjo, S., I. H. Utomo, dan J. Wiroatmodjo. 1984. Pengelolaan Gulma di Perkebunan. PT. Gramedia. Jakarta. $184 \mathrm{p}$. 